\title{
Molecular Alterations of Parotid Saliva in Infantile Chronic Recurrent Parotitis
}

\author{
IRENE MORALES-BOZO, BLANCA URZÚA-ORELLANA, MIRTHA LANDAETA, RAÚL MONTALBÁN, JIMENA TORRES, \\ ALVARO PINOCHET, GUSTAVO VALVERDE, AND ANDREA MUÑOZ-MARTÍNEZ
}

\begin{abstract}
Oral Biology and Biochemistry Laboratory [I.M-B., B.U-O., R.M., J.T., A.P., G.V.], Center for Oral Research (CIO), and Public Health Unit and Odontopediatrics Unit [A.M.M.], Faculty of Dentistry, University of Chile, PC-838-0492 Independencia, Santiago, Chile; and Pediatric Maxillofacial Surgery Division [M.L.], San Juan de Dios Hospital, Servicio Metropolitano de Salud Occidente, PC-835-0533, Santiago, Chile
\end{abstract}

\begin{abstract}
Infantile chronic recurrent parotitis (ICRP) is an insidious disease whose etiopathogenesis remains an enigma. Alterations in the physical appearance of parotid saliva from ICRP patients have been frequently reported. However, sialochemical studies in regard to ICRP are very rare. The aim of this study was to determine whether saliva of ICRP patients presents major physicochemical and biochemical alterations compared with saliva from paired healthy controls. Parotid, whole, and submandibular/sublingual saliva was collected at an asymptomatic stage from 33 ICRP patients (5-16 y old, both sexes) and from 33 sex- and age-matched healthy controls. Saliva was analyzed for protein concentration, mode of protein diffusion on cellulose membranes, unidimensional sodium dodecylsulfate (SDS)-polyacrylamide gel electrophoresis protein profiles and zymographic profiles of metalloproteinase 2 (MMP-2) and metalloproteinase 9 (MMP-9). Parotid saliva of ICRP patients showed an increased protein concentration, altered mode of protein diffusion, a higher frequency of polypeptide bands of $43,37,33,29,26,16$, and $10 \mathrm{kD}$, higher asymmetry in the polypeptide profiles of both contralateral parotid saliva, and an increase in the frequency of MMP-2 and MMP-9. Parotid saliva of patients with ICRP is molecularly altered with respect to normal saliva. Some of the molecular differences could be related to the etiopathogenesis of the disease. (Pediatr Res 61: 203-208, 2007)
\end{abstract}

$I^{\prime}$ CRP is an inflammatory disease associated with nonobstructive glandular sialectasia. It is characterized by recurrent episodes of swelling of one or both parotid glands that alternate with remission intervals lasting for weeks or months in which glands are clinically asymptomatic $(1,2)$. The onset of the disease usually occurs around age $3 \mathrm{y}$. Symptoms may diminish and disappear spontaneously after puberty. Sometimes the disease may persist until adulthood (1-3).

Among the postulated etiological factors of ICRP are congenital ductal malformations, genetic factors, allergies, bacterial infections, local manifestations of autoimmune disease, and immunodeficiencies $(1,2,4-9)$. However, none of them

Received April 18, 2006; accepted September 16, 2006.

Correspondence: Irene Morales-Bozo, DDS, MSc, Oral Biology and Biochemistry Laboratory, Center for Oral Research (CIO), Faculty of Dentistry, University of Chile, Olivos 943, PC-838-0492 Independencia, Santiago, Chile; e-mail: imorales@uchile.cl

This study was supported in part by University of Chile: Grants DI-MULT 05/35-2; DI-ODO 007/2 and PRI-ODO 04/23.

DOI: $10.1203 / p d r .0 b 013 e 31802 d 77 b 5$ has been demonstrated to play a causative role in the disease, and to date its etiopathogenesis remains an enigma.

Likewise, consensus on the therapeutic management of ICRP has yet to be achieved. Different specialists have opted for different therapies. Among the therapeutic indications described in the specialized literature is a diversity of physical maneuvers to stimulate the salivary flux (1) and pharmacotherapy with nonsteroid anti-inflammatory agents (7) in combination with sialogogues and/or antibiotics $(3,6,10)$. Recently, Nahlieli et al. (11) proposed an interventional approach using a sialendoscope. In cases in which irreversible damage has occurred, ligation of the excretory duct is indicated to produce glandular atrophy $(1,2)$. In severe cases, partial or total parotidectomy is prescribed as a last resource $(1,2,12)$.

Studies on glandular tissue obtained from patients with ICRP have shown lymphocytic infiltrates and lymphoid follicles around dilated interlobular ducts (sialectasia) $(1,13,14)$.

Most of the studies on ICRP describe qualitative changes in parotid saliva during the active period of the disease $(1,2,4,7)$. Some authors describe the salivary fluid either as mucopurulent (1), as a milky viscous secretion with the accumulation of semisolid material (2), as purulent and filamentous (4), or as a turbid and purulent material (7). If those physical changes of parotid saliva from ICRP patients could be associated with changes in its molecular composition, it might be expected to use parotid saliva as an indicator of the functional status of the gland. In that direction, the use of saliva for the diagnosis of disorders that affect salivary glands has been documented in regard to Sjögren syndrome, in therapeutic irradiation of the maxillofacial territory in cancer patients, and in cystic fibrosis (15-18). However, in the specialized literature, just a few sialochemical studies are referred to ICRP.

In 1978, Tabak et al. (19) analyzed parotid saliva of ICRP patients in which salivary concentrations of albumin and lactoferrin were increased during the acute episode and asymptomatic stage. Then in 1996, Ericson and Sjoback (20) analyzed samples of parotid saliva from 17 children with ICRP and observed a significant increase in the concentrations of albumin, $\operatorname{IgA}$, lactoferrin, and kallikrein in relation to saliva

Abbreviations: ICRP, infantile chronic recurrent parotitis; MMP-2, metalloproteinase 2; MMP-9, metalloproteinase 9 
from healthy controls. Both studies, however, are referred to a small group of proteins. Furthermore, to date, no sialochemical study approaches the analysis of proteins that could be related to the damage of salivary glands.

The aim of this study was to determine whether saliva of ICRP patients presents, in relation to saliva from paired healthy controls, major physicochemical and biochemical alterations. To this end, we assayed that saliva for modes of protein diffusion on cellulose membranes, total protein content, electrophoretic unidimensional polypeptide profiles, and occurrence of MMP-2 and MMP-9. We postulate that parotid saliva of ICRP patients displays major physicochemical and biochemical alterations.

\section{METHODS}

Subjects. Thirty-three ICRP patients under current surveillance at the Pediatric Maxillofacial Surgery Division of San Juan de Dios Hospital were included. Inclusion criteria were (a) at least two reported acute inflammatory episodes affecting the same parotid gland, (b) bilateral sialographic study, (c) absence of any systemic disease, and (d) normal appearance of gingiva, teeth, and oral mucosa. Patients were recruited at an asymptomatic stage of the condition and at various stages of the treatment. The control population consisted of 33 healthy volunteers under preventive dental care at the same hospital, paired by gender and age, who fulfilled the following criteria: (a) absence of any oral, glandular, or systemic disease and (b) no medication in the past 3 mo. The study was conducted according to the guidelines of the Ethics Committee of the Faculty of Dentistry, University of Chile. Informed consent was obtained from the parents at the beginning of the study.

Saliva collection. Saliva samples were collected by a single trained operator after $2 \%$ citric acid stimulation at about $0.900-11.00$ under standardized conditions (21). Whole saliva was expectorated into two collection vessels. Whole saliva collected during the first $30 \mathrm{~s}$ was excluded from protein analysis. Parotid and submandibular/sublingual saliva samples were collected by using adapted devices (22). Flow rates were estimated by scoring total saliva volumes and the corresponding collection times. Samples were maintained in ice-cooled containers during the collection and then were stored at $-20^{\circ} \mathrm{C}$ until their analysis.

Quantification of salivary proteins. Proteins were measured according to Bramhall et al. (23) with previously described modifications (24). Aliquots of saliva or bovine serum albumin $(10-50 \mu \mathrm{g})$ were spotted on cellulose disks (Whatman 1, diameter $2.5 \mathrm{~cm}$ ), fixed in 5\% trichloracetic acid, washed in $80 \%$ ethanol and 3:1 ethanol/ether, stained with Coomassie blue R-250, and washed in $7 \%$ acetic acid until clear background. The disks were photographed to keep records of the mode of diffusion (monophasic or biphasic) of the salivary protein (25). The blue dye of each disk was eluted in $45 \%$ methanol $/ 0.25 \%$ ammonia and subjected to spectrophotometry at $610 \mathrm{~nm}$.

Unidimensional electrophoresis. Aliquots of saliva ( $8.5 \mu \mathrm{g}$ protein) were fractionated in $10 \%$ SDS-polyacrylamide gels $\left(20 \times 20 \times 0.15 \mathrm{~cm}^{3}\right)$ according to Laemmli (26) and developed with Coomassie blue. Gels were calibrated by using broad range protein $M_{r}$ standards. Identification of individual bands was based on the apparent $M_{r}$. Samples of contralateral parotid glands of single subjects were run in neighbor tracks. Polypeptide bandings of parotid saliva samples from ICRP patients were compared with those of healthy controls. Also, the degree of concordance of polypeptide profiles (symmetry/asymmetry) between both parotid saliva samples of each subject was assessed.

Zymography. Aliquots of saliva (5 $\mu \mathrm{g}$ protein) were mixed with 60 $\mathrm{mmol} / \mathrm{L}$ Tris- $\mathrm{HCl} \mathrm{pH} 6.8,5 \%$ SDS, $20 \%$ glycerol, and $0.03 \%$ bromophenol blue and electrophoresed at constant $125 \mathrm{~V}$ according to Laemmli (26) in 10\% SDS-polyacrylamide gels containing $1 \mathrm{mg} / \mathrm{mL}$ gelatin. After fractionation, gels were incubated twice at room temperature for 20 min each in $2.5 \%$ Triton $\mathrm{X}-100$ and then incubated overnight at $37^{\circ} \mathrm{C}$ in activation buffer $(10 \mathrm{mmol} / \mathrm{L}$ Tris- $\mathrm{HCl}(\mathrm{pH} 8.0) / 1.25 \%$ Triton $\mathrm{X}-100 / 5 \mathrm{mmol} / \mathrm{L} \mathrm{CaCl} / 1 \mu \mathrm{mol} / \mathrm{L} \mathrm{ZnCl} \mathrm{Zn}_{2}$ ). Gels were stained in $0.25 \%$ Coomassie blue for $6 \mathrm{~h}$ and destained in $10 \%$ methanol/15\% acetic acid until clear bands were resolved. Gels were calibrated using $M_{r}$ standards. Nonmetalloproteinase proteases were discarded by incubating salivary samples in $50 \mathrm{mmol} / \mathrm{L} N$-ethylmaleimide $/ 50 \mathrm{mmol} / \mathrm{L}$ phenylmethylsulfonylfluoride Metalloproteinase activity was confirmed by incubating gels in activation buffer containing $5 \mathrm{mmol} / \mathrm{L}$ ethylenediamine tetraacetic acid, a metalloproteinase inhibitor. Further, metalloproteinase activities were contrasted against MMP-2 and MMP-9 standards.

Statistics. For age, flow rate, and protein concentration in saliva, averages and standard deviations were calculated. Statistical analyses were performed by a $t$ test or the Wilcoxon Mann-Whitney test as appropriate. For the mode of protein diffusion, presence of electrophoretic bands, symmetry/asymmetry, and presence of zymographic bands, frequencies were determined. In these cases, statistical analyses were performed by a $\chi^{2}$ or Fisher exact test as appropriate. Association between variables was assessed by logistic regression analysis. Stata Version 7.0 statistical software was used. Statistical significance was set at $p<0.05$.

\section{RESULTS}

Patients. A total of 66 subjects, 33 ICRP patients (12 female, 21 male) with an average age of $10.3 \pm 3.3$ y (range, 5-16) and 33 age- and sex-matched controls were studied (Table 1). Fourteen patients were affected bilaterally, and 19 expressed either right $(n=6)$ or left $(n=13)$ clinical manifestations of the disease (Table 2). Sialographic findings but not gender or age were associated with the laterality of the disease $[p<0.001$; odds ratio $(\mathrm{OR})=69.3][95 \%$ confidence interval $(\mathrm{CI})=12.9-372.7]$. Thus, bilateral parotid sialographic alterations were observed in 13 of 14 bilateral patients and ipsilateral alterations were detected in 18 of 19 unilaterally affected patients. The only exceptions were a bilateral patient displaying sialographic alterations only in the left parotid gland, two unilaterally affected patients displaying sialographic alterations also in the contralateral parotid gland, and a unilateral patient presenting normal sialographic images on both sides (Table 2).

Salivary samples. Whole saliva, submandibular/sublingual saliva, and both samples of parotid saliva from ICRP patients and healthy controls were pus free and blood free and displayed a translucid appearance. In the group of ICRP patients, 16 samples of parotid saliva had a whitish particulate material and eight had a viscous appearance. Mean value of flow rates of parotid saliva among the ICRP patients $(0.136 \mathrm{~mL} / \mathrm{min} /$ gland) was significantly lower $(p<0.001)$ than the one corresponding to the control group $(0.384 \mathrm{~mL} / \mathrm{min} / \mathrm{gland})$. Protein concentration in parotid saliva of ICRP patients showed statistically significant increases compared with healthy controls (Table 1).

Table 1. Age and sex distribution and protein concentration of parotid saliva among ICRP patients and controls

\begin{tabular}{cccccc}
\hline & \multicolumn{2}{c}{ Sex } & & \multicolumn{2}{c}{ Protein $(\mathrm{mg} / \mathrm{mL}) *$ mean \pm SD } \\
\cline { 2 - 3 } Group & $\mathrm{F}$ & $\mathrm{M}$ & Age $(\mathrm{y})$, mean \pm SD (range) & Right parotid & Left parotid \\
\hline Control $(n=33)$ & 12 & 21 & $9.4 \pm 2.4(4-14)$ & $0.554 \pm 0.186$ & $0.552 \pm 0.204$ \\
ICRP $(n=33)$ & 12 & 21 & $10.3 \pm 3.3(5-16)$ & $0.659 \pm 0.292 \dagger \neq$ & $0.693 \pm 0.304 \uparrow \S$ \\
\hline
\end{tabular}

* According to the method of Bramhall et al. (22) and using bovine seroalbumin as standard.

$\dagger$ Statistical significances of ICRP versus the corresponding control, Wilcoxon Mann-Whitney test.

$\ddagger p=0.034 ; \S p=0.010$. 
Table 2. Distribution of ICRP patients according to laterality of the disease and sialographic findings

\begin{tabular}{lccccc}
\hline & \multicolumn{2}{c}{ Right parotid sialography } & & \multicolumn{2}{c}{ Left parotid sialography } \\
\cline { 2 - 3 } \cline { 5 - 6 } Laterality* & Normal & Sialectasis & & Normal & Sialectasis \\
\hline Right $(n=6)$ & 0 & 6 & & 5 & 1 \\
Left $(n=13)$ & 12 & 1 & & 1 & 12 \\
Bilateral $(n=14)$ & 1 & 13 & & 0 & 14 \\
\hline
\end{tabular}

* Symptoms affecting either (left or right) or both parotid glands.

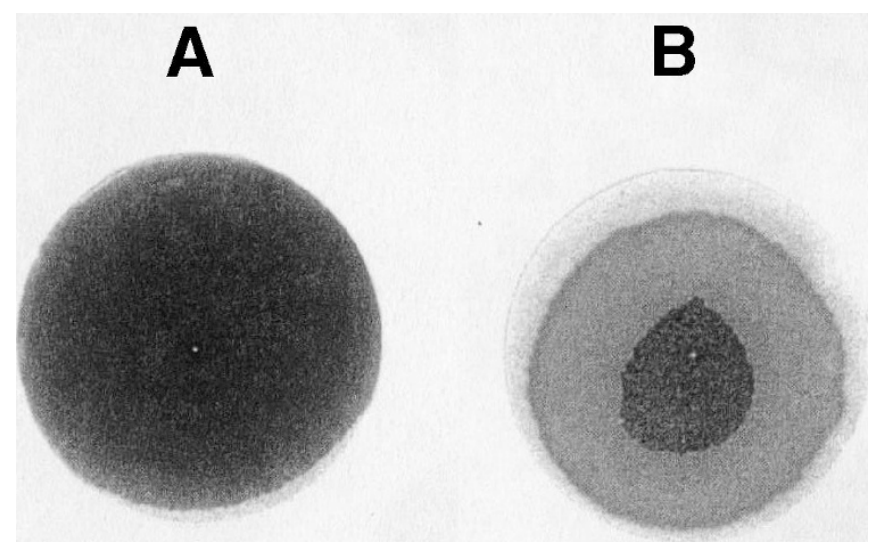

Figure 1. Modes of protein diffusion of salivary protein on cellulose paper membranes. Aliquots of parotid saliva $(A)$ or submandibular/sublingual saliva $(B)$ were placed on the center of a disk, fixed, and stained. Monophasic $(A)$ and biphasic $(B)$ modes of protein diffusion.

Diffusion assay of salivary proteins. Protein of different types of saliva display different modes of diffusion when placed punctually on cellulose laminar matrices (25). Thus, parotid saliva from healthy glands presents a monophasic mode of diffusion that is characterized by a homogeneous radial distribution of the protein on the cellulose lamina (Fig. $1 A$ ). In contrast, the samples of submandibular/sublingual and whole saliva displayed biphasic diffusion modes in which a nondiffusible central protein fraction becomes surrounded by a peripheral, radially diffusible protein fraction (Fig. $1 B$ ). In the present study, those observations including the analysis of various types of saliva from 33 healthy subjects were mostly corroborated. Thus, among these subjects, 30 right parotid saliva samples and 32 left parotid saliva samples showed a monophasic diffusion mode. Whole and submandibular/ sublingual saliva samples from all the control subjects $(n=$ 33) displayed a biphasic mode of diffusion. When saliva samples from the ICRP patients were subjected to this anal-
Table 4. Mode of diffusion of parotid saliva in relation to the laterality of the disease among ICRP patients

\begin{tabular}{lcccc}
\hline & \multicolumn{4}{c}{ Mode of protein diffusion of parotid saliva } \\
\cline { 2 - 5 } \multicolumn{1}{c}{ Laterality } & $\begin{array}{c}\text { Biphasic } \\
\text { right }\end{array}$ & $\begin{array}{c}\text { Biphasic } \\
\text { left }\end{array}$ & $\begin{array}{c}\text { Both } \\
\text { biphasic }\end{array}$ & Monophasic \\
\hline Right $(n=6)$ & 0 & 0 & 6 & 0 \\
Left $(n=13)$ & 1 & 1 & 8 & 3 \\
Bilateral $(n=14)$ & 1 & 1 & 11 & 1 \\
Total $(n=33)$ & 2 & 2 & 25 & 4 \\
\hline
\end{tabular}

Results in this table show the number of patients displaying either monophasic or biphasic modes of protein diffusion in either parotid saliva sample in relation to the laterality of the disease.

ysis, some striking differences were observed. On the one hand, both whole and submandibular/sublingual saliva samples from those patients expressed the biphasic mode of diffusion as it normally occurs among healthy subjects. In contrast, 27 of 33 ICRP patients (82\%) displayed a biphasic mode of diffusion in at least one of their parotid saliva samples. Clearly, the frequencies of parotid saliva showing the biphasic mode of diffusion in both groups under study were statistically different (Fisher exact test, $p<0.001$, Table 3 ). Furthermore, regardless the laterality of the ICRP disease in the population under study, 25 of the 33 ICRP patients displayed a biphasic mode of diffusion both in their left and right parotid saliva samples (Table 4).

Electrophoretic profiles of salivary proteins in ICRP patients. A direct comparison of the unidimensional electrophoretic protein profiles of parotid saliva samples in our healthy and ICRP groups showed marked differences as to the frequency of a few polypeptide bands. Those were the ones whose apparent molecular weights were 43, 37, 33, 29, 26, 16, and $10 \mathrm{kD}$. All of them were more frequent among the ICRP patients compared with healthy controls (Fisher exact test, $p<$ 0.05 , Table 5). No single change in polypeptide bands was identified in all the ICRP patients (Fig. 2, Table 5). However, 23 of the 31 ICRP patients displaying the $10-\mathrm{kD}$ polypeptide band showed that polypeptide in the saliva produced by the healthy gland. That observation sustained an association between that polypeptide band and the clinic commitment of the gland $(p=0.011 ; \mathrm{OR}=0.22)(95 \% \mathrm{CI}=0.68-0.71)$.

On the other hand, a band-by-band comparative analysis of the protein profiles displayed by the right and the left parotid saliva samples from the same subject allowed us to define the occurrence or absence of symmetry. From an operational point

Table 3. Mode of protein diffusion of both whole and glandular saliva samples from ICRP patients and healthy controls

\begin{tabular}{|c|c|c|c|c|c|c|c|c|}
\hline Group & \multicolumn{8}{|c|}{ Saliva } \\
\hline Control $(n=33)$ & 30 & 3 & 32 & 1 & 0 & 33 & 0 & 33 \\
\hline $\operatorname{ICRP}(n=33)$ & $6^{*}$ & $27 *$ & $6^{*}$ & $27 *$ & $0 \dagger$ & $33 \dagger$ & $0 \dagger$ & $33 \dagger$ \\
\hline
\end{tabular}

Mono, monophasic; Bi, biphasic; SBM/SL, submandibular/sublingual.

Results in this table show the number of saliva samples displaying either a monophasic or a biphasic mode of protein diffusion. Statistical significance of ICRP versus the corresponding control was assessed by the Fisher exact probability test.

$* p<0.001 ; \dagger \mathrm{NS}$. 
Table 5. Distribution of individual polypeptide bands in parotid saliva from ICRP patients and healthy controls

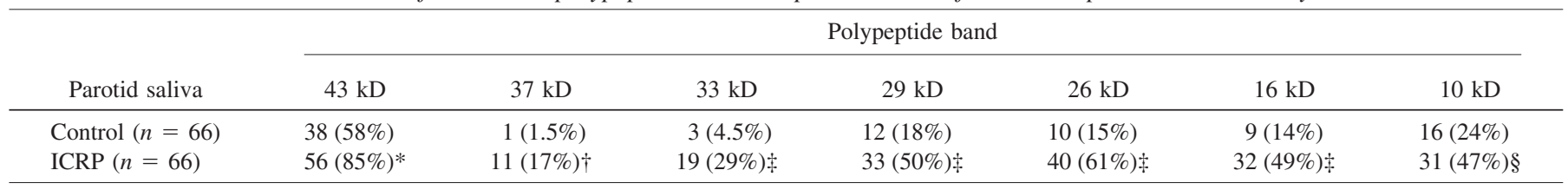

Results in this table show the number of samples in which each selected polypeptide band was observed (percentage in brackets). Statistical significance was assessed by the Fisher exact probability test.

$* p=0.001 ; \dagger p=0.004 ; \ddagger p<0.001 ; \S p=0.011$.

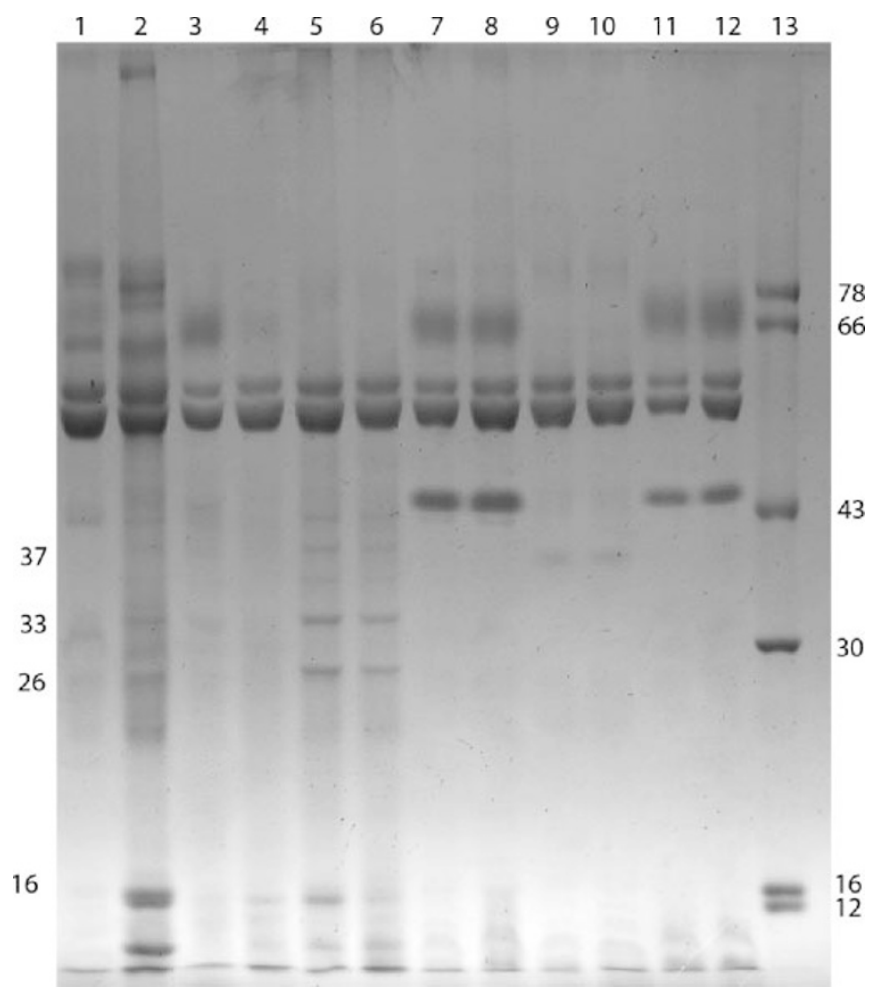

Figure 2. Representative gel of the electrophoretic fractionation of parotid saliva from healthy controls and ICRP patients. Both samples from each subject were run in neighbor lanes. Odd lanes correspond to right parotid saliva samples and even lanes to left parotid saliva samples. Lanes 1-6 show the polypeptide profiles of three ICRP patients and lanes 7-12 the profiles corresponding to three healthy controls. Lane 13 shows $M_{r}$ standards. On the left, polypeptide bands differing in frequency in the ICRP and control groups are shown.

of view, we considered symmetry when the number of polypeptide bands distinguishing both parotid saliva samples was between 0 and 3 and asymmetry when the number of differences was four or more. Under these considerations, most of the healthy subjects included in the study (25 of 33) exhibited symmetry, whereas most of the ICRP patients (23 of 33 ) exhibited asymmetry ( $\chi^{2}$ test, $p<0.001$ ) (Fig. 2, Table 6).

MMP-2 and MMP-9 in saliva of ICRP patients. The presence or absence of clear bands having identical mobility as pure metalloproteinases MMP-2 and MMP-9 (92 and 72 $\mathrm{kD}$, respectively) was determined. In the control group, MMP-9 was observed in the right and left parotid saliva samples of only two of 33 subjects, whereas it was present in the whole saliva of 21 subjects and in the submandibular/ sublingual saliva of 13 subjects. In contrast, in the group of 33 ICRP patients, MMP-9 was observed in the right parotid saliva of 16 subjects and in the left parotid saliva of 18
Table 6. Subjects expressing symmetry or asymmetry in the polypeptide profile of both contralateral parotid saliva samples among healthy controls and ICRP patients

\begin{tabular}{ccc}
\hline Group & Symmetry & Asymmetry \\
\hline Control $(n=33)$ & 25 & 8 \\
$\operatorname{ICRP}(n=33)$ & $10^{*}$ & $23^{*}$ \\
\hline
\end{tabular}

Results in this table show the number of subjects in the control and ICRP groups displaying symmetry or asymmetry. Statistical significance was assessed by the $\chi^{2}$ test.

$* p<0.001$.

subjects, whereas it was detected in whole saliva of 25 subjects and in the submandibular/sublingual saliva of 18 subjects. The frequency of ICRP subjects presenting MMP-9 either in the right or left parotid saliva samples was statistically different from the control group (Fisher exact test, $p<$ 0.05 ) (Table 7, Fig. 3). Likewise, among the healthy subjects, MMP-2 was observed in the right and left parotid saliva samples of only two subjects, whereas it was observed in whole saliva and submandibular/sublingual saliva samples of 17 and eight subjects, respectively. When saliva from 33 ICRP patients was studied, MMP-2 was detected in the right and left parotid saliva samples of eight and 13 subjects, respectively, and in whole saliva and submandibular/sublingual saliva of 14 and eight subjects, respectively. The frequency of ICRP subjects presenting MMP-2 in the left parotid saliva was significantly different from that corresponding to the control group (Fisher exact test, $p=0.003$ ). Comparison of right parotid saliva samples from ICRP and control subjects resulted in no statistical difference $(p=0.082)$ (Table 7, Fig. 3). Among ICRP patients, MMP-2 but not MMP-9 was significantly associated with the clinic commitment of the parotid gland $(p=0.031 ; \mathrm{OR}=3.8 ; 95 \% \mathrm{CI}=1.1-13.0)$.

\section{DISCUSSION}

ICRP is a pathology of unknown etiology. Direct study of the affected parotid tissue is restricted due to its close imbrication with the facial nerve. Thus, molecular analysis of parotid secretion could offer a valuable complement to the study of the disease as well as to the noninvasive assessment of the glandular function. These aims would need to demonstrate first that parotid saliva is in fact affected in ICRP patients when compared with parotid saliva from healthy subjects. In the present study, some major physicochemical and biochemical alterations in the parotid saliva of ICRP patients were shown. First, parotid saliva of ICRP patients was shown to present a higher protein concentration compared with saliva from a control group. These results differ from 
Table 7. Subjects expressing metalloproteinases in whole and glandular saliva samples among ICRP patients and healthy controls

\begin{tabular}{|c|c|c|c|c|c|c|c|c|}
\hline Group & \multicolumn{8}{|c|}{ Presence of salivary metalloproteinase activity } \\
\hline Control $(n=33)$ & 2 & 2 & 2 & 2 & 13 & 8 & 21 & 17 \\
\hline $\operatorname{ICRP}(n=33)$ & $16^{*}$ & $8 \dagger$ & $18^{*}$ & $13 \ddagger$ & $18 \S$ & $8 \S$ & $25 \S$ & $14 \S$ \\
\hline
\end{tabular}

Results in this table show the number of control and ICRP subjects expressing each of those proteases in the various types of saliva. Statistical significance of ICRP versus the corresponding control was assessed by the Fisher exact probability test.

$* p<0.001 ; \dagger p=0.082 ; \ddagger p=0.003 ; \S \mathrm{NS}$.

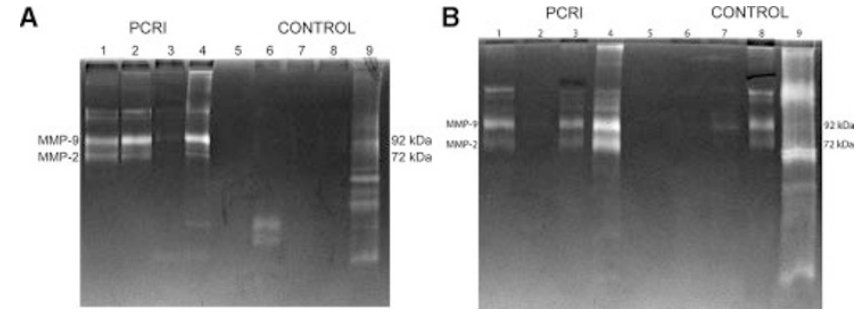

Figure 3. Representative zymography gels for metalloproteinases MMP-2 and MMP-9 in whole and glandular saliva samples from healthy controls and ICRP patients. (A) Lanes 1-4 and 6-9 correspond, respectively, to the right and left parotid, submandibular/sublingual, and whole saliva samples from an ICRP patient and from a healthy subject. (B) Samples corresponding to a different ICRP patient and to a different healthy subject. Clear bands corresponding to metalloproteinases MMP-2 and MMP-9 are shown.

those of Ericson and Sjoback (20) who found no statistical differences in the total protein concentration but higher concentrations of salivary albumin, IgA, lactoferrin, and kallikrein between both groups under study. Higher protein concentration of parotid saliva could be due to an increase in the secretory protein that is synthesized by the gland, to leakage of plasmatic proteins, or to a decrease in the water content of saliva $(17,27,28)$. Although additional molecular analyses are necessary to explain such an increase in protein concentration, the alteration in this biochemical parameter may well be indicative of a functional failure of the gland.

In the present study, we adapted a physicochemical approach to characterize qualitatively the salivary fluids. Saliva diffuses radially from the spotting site when placed punctually on cellulose membranes. After staining, the mode of diffusion displayed by the salivary protein allowed us to make a clear distinction between different types of saliva (25). Parotid saliva is a serous fluid whose protein diffuses homogeneously. On the contrary, submandibular/sublingual saliva and whole saliva exhibit viscoelastic properties that have been related to the presence of the MG1 and MG2 mucins and to intermolecular interactions between them and with other salivary macromolecules $(29,30)$. Both salivary subtypes display a biphasic mode of diffusion (25). In our study, 32 left parotid saliva samples and 30 right parotid saliva samples from 33 healthy subjects (about 94\%) showed normal monophasic mode of diffusion. Strikingly, about $82 \%$ of parotid saliva samples from ICRP patients showed a biphasic mode of protein diffusion (Fig. 1, Table 3). That observation was in accordance with the altered physical characteristics of parotid saliva that we have observed in these patients and also previ- ously described by various laboratories $(1,2,5,9)$. Moreover, that biphasic mode of diffusion displayed by this saliva was found to be sensitive to disulfide-bridge disrupters (unpublished observations). Our results suggest that at least a fraction of the protein components of parotid saliva from ICRP patients displays a more complex supramolecular nondiffusible protein organization. Again, that new organization may have different origins that would vary from the massive occurrence of new protein components to the occurrence of just a few molecular changes in the protein composition that may lead to a cascade of new intermolecular interactions. More surprisingly in this part of the study was finding that the mode of diffusion of parotid salivary protein of most of the ICRP patients (25 of 33) was affected bilaterally regardless of laterality of the clinical condition (Table 4). Although we have no definite explanation for this observation, our results tempt us to speculate that the healthy contralateral parotid gland of unilaterally affected ICRP patients is also subclinically affected. Studies in that direction are currently under development in our laboratory.

Unidimensional electrophoretic analysis of parotid saliva from ICRP patients showed that bands of 43, 37, 33, 29, 26, 16 , and $10 \mathrm{kD}$ were expressed in a frequency significantly higher than among healthy controls. It remains to be seen whether some of those polypeptides may account for the alterations in the physical properties of parotid saliva in ICRP patients. In the same regard, it would be interesting to get more insight into the $10-\mathrm{kD}$ band given its higher frequency in saliva produced by the healthy parotid gland of ICRP patients. Conversely, at variance with the marked bilateral symmetry of polypeptide bandings of parotid saliva samples among healthy controls, parotid saliva samples from ICRP patients were found to be highly asymmetric. This was another main characteristic of parotid saliva in ICRP patients. As in the mode of diffusion of parotid salivary proteins, the increased asymmetry was unrelated to the laterality of the pathologic condition.

The study of more specific protein molecules and the expected damage of the parotid parenchyma in ICRP led us to study MMP-2 and MMP-9 in parotid saliva of ICRP patients (31). Those activities had been previously described in whole saliva of healthy subjects (15). Studies on metalloproteinases involving glandular saliva are rather scarce and have been restricted to low numbers of subjects $(32,33)$. In agreement with previous reports, we found that more than $50 \%$ of the whole saliva samples from healthy subjects presented MMP-2 and MMP-9 activity. However, only two 
healthy subjects expressed that activity in parotid saliva, thus suggesting that either these proteins are in fact absent in this glandular fluid or they are present in parotid saliva of a small percentage of the normal population. We are unaware of whether both MMP-2- and MMP-9-positive subjects were subclinical carriers of a glandular disease. Contamination of parotid saliva of both positive healthy subjects by total saliva was ruled out since MMPs zymography studies of their total saliva were markedly different from those of their parotid saliva (not shown). By contrast, when the presence of MMP-2 and MMP-9 was studied in parotid saliva from ICRP patients, about a third of them (21 of 66) demonstrated MMP-2 activity and about a half (34 of 66) demonstrated MMP-9 activity. MMP-2 was found to be associated with the clinical commitment of the parotid gland since in 14 of the 21 ICRP patients displaying that enzyme, it was detected in the saliva produced by the altered gland. By contrast, despite its higher frequency, MMP-9 was not associated with the clinical condition of the gland since it was observed indistinctly both in healthy and altered parotid glands of ICRP patients. Previous studies had reported the presence of both enzymes in mixed whole saliva of patients affected by conditions that alter salivary glands $(15,16)$. Our study reports for the first time that the frequency of subjects displaying MMP-2 and MMP-9 activities in parotid saliva is much higher among ICRP patients than among healthy subjects. A leading study in parotid saliva of Sjögren syndrome patients had also shown a marked increase in MMP-2 and MMP-9 expression (32). These metalloproteinases have been associated with tissue destruction in periodontitis, dentinal caries lesion progression, and a variety of other oral diseases (31). Thus, MMP-2 and MMP-9 may be involved in the etiopathology of the parotid damage in ICRP patients. On this basis, complementary studies on the quantification of MMP-2 and MMP-9 enzyme activities, the assessment of active and latent molecular forms of these enzymes and the MMPs/ TIMPs (tissue inhibitors of metalloproteinases) balance are currently being addressed. On the other hand, previous reports have shown that in vitro stimulation of a human salivary gland cell line by interferon- $\gamma$ and tumor necrosis factor $\alpha$ provokes an increase in the expression and secretion of MMP-2 and MMP-9 (32). Thus, studies on the presence of particular cytokines and growth factors in parotid saliva of ICRP patients may also help us to gain valuable insight into the disease $(32,34)$. Also, the possibility of inhibition of metalloproteinases by synthetic inhibitors with the aim of limiting parotid tissue destruction in ICRP patients might be evaluated (31). Thus, our results have clearly demonstrated that parotid saliva in ICRP patients is altered with respect to normal saliva and that some of the molecular differences could be related to the etiopathogenesis of the medical condition and may be of uppermost relevance to the management of ICRP.

Acknowledgments. The authors are grateful of Dr. M.A. Valenzuela for providing MMP-2 and MMP-9 markers and Dr. R.O. López-Solís for helpful discussion of the manuscript.

\section{REFERENCES}

1. Chitre VV, Premchandra DJ 1997 Recurrent parotitis. Arch Dis Child 77:359-363

2. Baurmash HD 2004 Chronic recurrent parotitis: a closer look at its origin, diagnosis, and management. J Oral Maxillofac Surg 62:1010-1018

3. Concheiro A, Bellver E, Garrido R, Garcia Tornel S 2000 Chronic recurrent parotitis in childhood. An Esp Pediatr 53:418-421

4. Vinagre C, Martínez MJ, Avendaño LF, Landaeta M, Pinto ME 2003 Virology of infantile chronic recurrent parotitis in Santiago de Chile. J Med Virol 70:459-462

5. Giglio MS, Landaeta M, Pinto ME 1997 Microbiology of recurrent parotitis. Pediatr Infect Dis J 16:386-390

6. Shkalim V, Monselise Y, Mosseri R, Finkelstein Y, Garty BZ 2004 Recurrent parotitis in selective IgA deficiency. Pediatr Allergy Immunol 15:281-283

7. Fazekas T, Wiesbauer P, Schroth B, Potschger U, Gadner H, Heitger A 2005 Selective IgA deficiency in children with recurrent parotitis of childhood. Pediatr Infect Dis J 24:461-462

8. Kolho KL, Saarinen R, Paju A, Stenman J, Stenman UH, Pitkaranta A 2005 New insights into juvenile parotitis. Acta Paediatr 94:1566-1570

9. Leerdam CM, Martin HC, Isaacs D 2005 Recurrent parotitis of childhood. J Paediatr Child Health 41:631-634

10. Isaacs D 2002 Recurrent parotitis. J Paediatr Child Health 38:92-94

11. Nahlieli O, Shacham R, Shlesinger M, Eliav E 2004 Juvenile recurrent parotitis: a new method of diagnosis and treatment. Pediatrics 114:9-12

12. Moody AB, Avery CM, Walsh S, Sneddon K, Langdon JD 2000 Surgical management of chronic parotid disease. Br J Oral Maxillofac Surg 38:620-622

13. Ussmuller J, Donath K 1999 Clinical, histopathologic and immunohistochemical studies of chronic sialectatic parotitis in childhood and adolescence. Klin Padiatr 211:165-171

14. Shimizu M, Ussmuller J, Donath K, Yoshiura K, Ban S, Kanda S, Ozeki S, Shinohara M 1998 Sonographic analysis of recurrent parotitis in children: a comparative study with sialographic findings. Oral Surg Oral Med Oral Pathol Oral Radiol Endod 86:606-615

15. Asatsuma M, Ito S, Watanabe M, Takeishi H, Nomura S, Wada Y, Nakano M, Gejyo F, Igarashi A 2004 Increase in the ratio of metalloproteinase-9 to tissue inhibitor of metalloproteinase-1 in saliva from patients with primary Sjögren's syndrome. Clin Chim Acta 345:99-104

16. Vuotila T, Ylikontiola L, Sorsa T, Luoto H, Hanemaaijer R, Salo T, Tjaderhane L 2002 The relationship between MMPs and $\mathrm{pH}$ in whole saliva of radiated head and neck cancer patients. J Oral Pathol Med 31:329-338

17. Kaufman E, Lamster IB 2002 The diagnostic applications of saliva-a review. Crit Rev Oral Biol Med 13:197-212

18. Streckfus CF, Bigler LR 2002 Saliva as a diagnostic fluid. Oral Dis 8:69-76

19. Tabak L, Mandel ID, Karlan D, Baurmash H 1978 Related 1978 alterations in lactoferrin in salivary gland disease. J Dent Res 57:43-47

20. Ericson S, Sjoback I 1996 Salivary factors in children with recurrent parotitis. Part 2: protein, albumin, amylase, IgA, lactoferrin, lysozyme and kallikrein concentrations. Swed Dent J 20:199-207

21. Atkinson JC, Dawes C, Ericson T, Fox PC, Gandara BK, Malamud D, Mandel ID, Navazesh M, Tabak LA 1993 Guidelines for saliva nomenclature and collection. Ann N Y Acad Sci 694:1-348

22. Morales I, Domínguez P, López RO 1998 Dispositivos para colección de saliva de las glándulas salivales mayores. Resultados en sujetos normales. Rev Med Chil $126: 538-547$

23. Bramhall S, Noack N, Wu M, Loewenberg JR 1969 A simple colorimetric method for determination of protein. Anal Biochem 31:146-148

24. Durham JP, López-Solís R 1979 Effect of sodium hydroxide upon protein binding to filter paper disks and its significance in the determination of protein in colorimetric and radioisotopic assays. Anal Biochem 100:98-99

25. López RO, Morales I, Aguilera S 1998 Patrones de difusión de proteínas de la saliva humana. Rev Med Chil 126:1065-1072

26. Laemmli UK 1970 Cleavage of structural proteins during the assembly of the head of bacteriophage T4. Nature 227:680-685

27. Humphrey SP, Williamson RT 2001 A review of saliva: normal composition, flow and function. J Prosthet Dent 85:162-169

28. Turner RJ, Sugiya H 2002 Understanding salivary fluid and protein secretion. Oral Dis 8:3-11

29. Becerra L, Soares RV, Bruno LS, Siqueira CC, Oppenheim FG, Offner GD, Troxler RF 2003 Patterns of secretion of mucins and non-mucin glycoproteins in human submandibular/sublingual secretion. Arch Oral Biol 48:147-154

30. Soares RV, Siqueira CC, Bruno LS, Oppenheim FG, Offner GD, Troxler RF 2003 MG2 and lactoferrin form a heterotypic complex in salivary secretions. J Dent Res $82: 471-475$

31. Sorsa T, Tjaderhane L, Salo T 2004 Matrix metalloproteinases (MMPs) in oral diseases. Oral Dis 10:311-318

32. Wu AJ, Lafrenie R, Park C, Apinhasmit W, Chen Z, Birkedal-Hansen H, Yamada K, Stetler-Stevenson W, Baum B 1997 Modulation of MMP-2 (gelatinase A) and MMP-9 (gelatinase B) by interferon- $\gamma$ in a human salivary gland cell line. J Cell Physiol 171:117-124

33. Makela M, Salo T, Uitto VJ, Larjava H 1994 Matrix metalloproteinases (MMP-2 and MMP-9) of the oral cavity: cellular origin and relationship to periodontal status. J Dent Res 73:1397-1406

34. Curry TE Jr, Osteen K 2003 The matrix metalloproteinase system: changes, regulation and impact throughout the ovarian and uterine reproductive cycle. Endocr Rev $24: 428-465$ 